\title{
Optically healable supramolecular polymers
}

\author{
Mark Burnworth ${ }^{1}$, Liming Tang ${ }^{1}$, Justin R. Kumpfer ${ }^{1}$, Andrew J. Duncan ${ }^{2}$, Frederick L. Beyer ${ }^{2}$, Gina L. Fiore ${ }^{3}$, Stuart J. Rowan ${ }^{1}$ \\ \& Christoph Weder ${ }^{1,3}$
}

Polymers with the ability to repair themselves after sustaining damage could extend the lifetimes of materials used in many applications $^{1}$. Most approaches to healable materials require heating the damaged area $^{2-4}$. Here we present metallosupramolecular polymers that can be mended through exposure to light. They consist of telechelic, rubbery, low-molecular-mass polymers with ligand end groups that are non-covalently linked through metal-ion binding. On exposure to ultraviolet light, the metal-ligand motifs are electronically excited and the absorbed energy is converted into heat. This causes temporary disengagement of the metal-ligand motifs and a concomitant reversible decrease in the polymers' molecular mass and viscosity ${ }^{5}$, thereby allowing quick and efficient defect healing. Light can be applied locally to a damage site, so objects can in principle be healed under load. We anticipate that this approach to healable materials, based on supramolecular polymers and a light-heat conversion step, can be applied to a wide range of supramolecular materials that use different chemistries.

The healing of cracks in amorphous polymers by heating above the glass transition temperature $\left(T_{\mathrm{g}}\right)$ involves surface rearrangement and approach of polymer chains, followed by wetting, diffusion and reentanglement of the chains ${ }^{6}$. Because the rates of the final two steps are inversely proportional to the molecular mass, healing is generally slow and inefficient. This problem can be overcome by exploiting thermally reversible, covalent bonds ${ }^{7,8}$ or non-covalent supramolecular motifs ${ }^{5,9,10}$ that allow the reaction equilibrium to be temporarily shifted to lower-molecular-mass species ${ }^{11}$ on exposure to heat. This reduces the viscosity of the material, such that defects can be mended, before the equilibrium is shifted back and the polymer is reformed. Supramolecular polymers that phase separate into physically crosslinked networks (Fig. 1a) should be especially well suited for this purpose, because such morphologies generally bestow the material with high toughness. The supramolecular motifs can disengage in the solid state on exposure to heat or a competitive binding agent ${ }^{12,13}$, causing disassembly into small molecules ${ }^{14}$ and viscosity reductions. Reporting a series of supramolecular materials formed by metal-ligand interactions, we demonstrate here that this architecture is an excellent basis for elastomeric materials in which defects can be efficiently repaired. We show that the use of light ${ }^{15}$ as a stimulus for the dissociation of supramolecular motifs has distinct advantages over thermally healable systems, including the possibility of exclusively exposing and healing the damaged region.

The new polymers are based on a macromonomer comprising a rubbery, amorphous poly(ethylene-co-butylene) core with 2,6-bis $\left(1^{\prime}\right.$ methylbenzimidazolyl)pyridine (Mebip) ligands at the termini (Fig. 1b, 3). This design was based on the assumption that the hydrophobic core and the polar metal-ligand motif would phase separate ${ }^{16}$. Metal-Mebip complexes were previously used to self-assemble polymeric materials ${ }^{17-21}$, and their optical properties seemed appropriate for optical healing ${ }^{22}$ (see below). To probe how the metal ion affects the materials' properties, 3 was self-assembled with $\mathrm{Zn}\left(\mathrm{NTf}_{2}\right)_{2}$ or

a

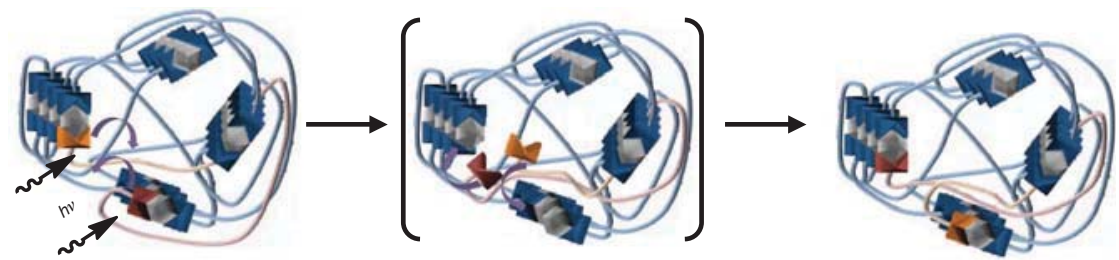

b
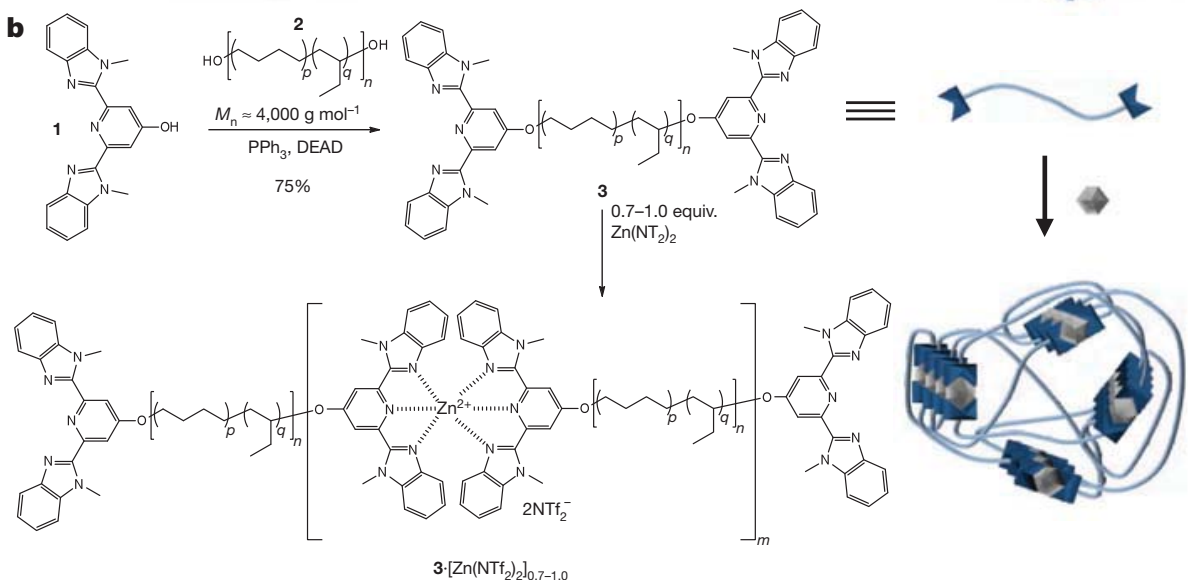

Figure $1 \mid$ Mechanism and synthesis of photohealable metallosupramolecular polymers. a, Proposed optical healing of a metallosupramolecular, phaseseparated network. $\mathbf{b}$, Synthesis of macromonomer 3 and polymerization by addition of $\mathrm{Zn}\left(\mathrm{NTf}_{2}\right)_{2}$. DEAD, diethyl azodicarboxylate.

${ }^{1}$ Department of Macromolecular Science and Engineering, Case Western Reserve University, 2100 Adelbert Road, Cleveland, Ohio 44106-7202, USA. ${ }^{2}$ US Army Research Laboratory, Aberdeen Proving Ground, Maryland 21005-5069, USA. ${ }^{3}$ Adolphe Merkle Institute and Fribourg Center for Nanomaterials, University of Fribourg, CH-1700 Fribourg, Switzerland. 
$\mathrm{La}\left(\mathrm{NTf}_{2}\right)_{3} \cdot \mathrm{La}^{3+}$ ions form weaker, more dynamic 3:1 complexes with Mebip than do $\mathrm{Zn}^{2+}$ ions, which bind to this ligand in a $2: 1$ ratio $^{13,23}$. Bistriflimide $\left(\mathrm{NTf}_{2}{ }^{-}\right.$) was chosen as the counterion because of its thermal stability and non-coordinating nature. The combination of equimolar amounts of $\mathrm{Zn}\left(\mathrm{NTf}_{2}\right)_{2}$ and 3 in solution caused a rapid viscosity increase, indicative of supramolecular assembly (this polymer is denoted as $\left.\mathbf{3} \cdot\left[\mathrm{Zn}\left(\mathrm{NTf}_{2}\right)_{2}\right]_{1.0}\right)$. Solvent evaporation and compression moulding resulted in colourless elastic films that, unlike 3 , have appreciable mechanical properties. Using the same procedure, polymers with $\mathrm{Zn}^{2+}: 3$ ratios of $0.9-0.7$ were also made $\left(3 \cdot\left[\mathrm{Zn}\left(\mathrm{NTf}_{2}\right)_{2}\right]_{0.9}\right.$, $\mathbf{3} \cdot\left[\mathrm{Zn}\left(\mathrm{NTf}_{2}\right)_{2}\right]_{0.8}$ and $\left.\mathbf{3} \cdot\left[\mathrm{Zn}\left(\mathrm{NTf}_{2}\right)_{2}\right]_{0.7}\right)$.

Small-angle X-ray scattering (SAXS) and transmission electron microscopy (TEM) studies of films of $\mathbf{3} \cdot\left[\mathrm{Zn}\left(\mathrm{NTf}_{2}\right)_{2}\right]_{x}$ revealed microphase-separated lamellar morphologies in which the metal-ligand complexes form a 'hard phase' that physically crosslinks the poly (ethylene-co-butylene) 'soft' domains. The SAXS data (Fig. 2a and Supplementary Table 1) show strong Bragg diffraction maxima at integer multiples of the scattering vector magnitude of the primary diffraction peak $\left(2 q^{*}, 3 q^{*}\right.$ and so on), characteristic of well-ordered layered morphologies. The lamellar period increased from $8.3 \mathrm{~nm}$ for $3 \cdot\left[\mathrm{Zn}\left(\mathrm{NTf}_{2}\right)_{2}\right]_{1.0}$ to $9.3 \mathrm{~nm}$ for $\mathbf{3} \cdot\left[\mathrm{Zn}\left(\mathrm{NTf}_{2}\right)_{2}\right]_{0.7}$ as the $\mathrm{Zn}^{2+}: \mathbf{3}$ ratio decreased. Concomitantly, the number of strong reflections decreased from four to two, indicating a reduction of long-range order. TEM experiments (Fig. 2b and Supplementary Fig. 2) confirmed the SAXS data.

The thermomechanical properties of $\mathbf{3}$ and $\mathbf{3} \cdot\left[\mathrm{Zn}\left(\mathrm{NTf}_{2}\right)_{2}\right]_{x}$ were probed by modulated differential scanning calorimetry (MDSC; Supplementary Fig. 3) and dynamic mechanical thermal analysis (DMTA; Supplementary Fig. 4). The MDSC trace of $\mathbf{3}$ shows reversible
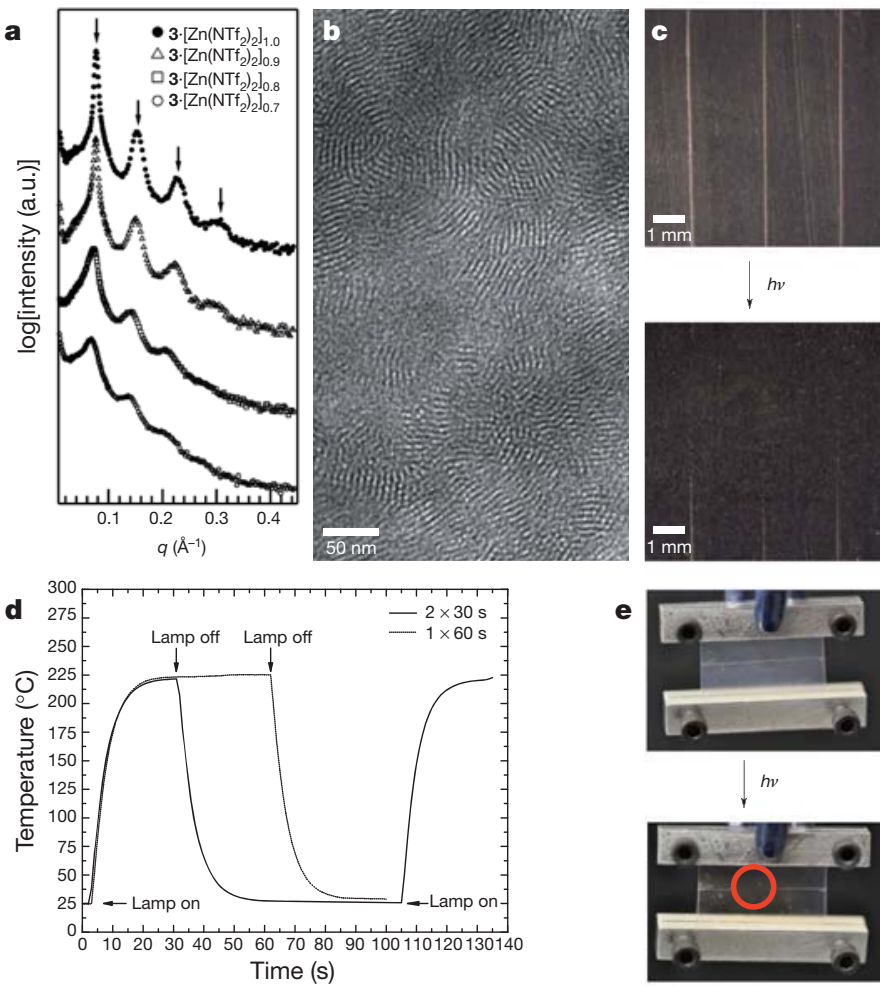

Figure $2 \mid$ Characterization of $\mathrm{Zn}$-based metallosupramolecular polymers. a, SAXS data for metallosupramolecular polymers of $\mathbf{3}$ and varying amounts of $\mathrm{Zn}\left(\mathrm{NTf}_{2}\right)_{2}$, shifted vertically for clarity. $\mathbf{b}$, Representative TEM micrograph showing the lamellar morphology of $\mathbf{3} \cdot\left[\mathrm{Zn}\left(\mathrm{NTf}_{2}\right)_{2}\right]_{1.0} \cdot \mathbf{c}$, Optical healing of $3 \cdot\left[\mathrm{Zn}\left(\mathrm{NTf}_{2}\right)_{2}\right]_{0.7}$ on exposure to light in the wavelength range $320-390 \mathrm{~nm}$ for $30 \mathrm{~s}$ twice at an intensity of $950 \mathrm{~mW} \mathrm{~cm}^{-2}$. d, Surface temperature of $3 \cdot\left[\mathrm{Zn}\left(\mathrm{NTf}_{2}\right)_{2}\right]_{0.7}$ on irradiation under the same conditions, as a function of time. e, Optical healing of $3 \cdot\left[\mathrm{Zn}\left(\mathrm{NTf}_{2}\right)_{2}\right]_{0.7}$ while under a load of $\sim 8 \mathrm{kPa}$ (width, $21 \mathrm{~mm}$; thickness, $0.31 \mathrm{~mm}$; mass, $5.25 \mathrm{~g}$ ).
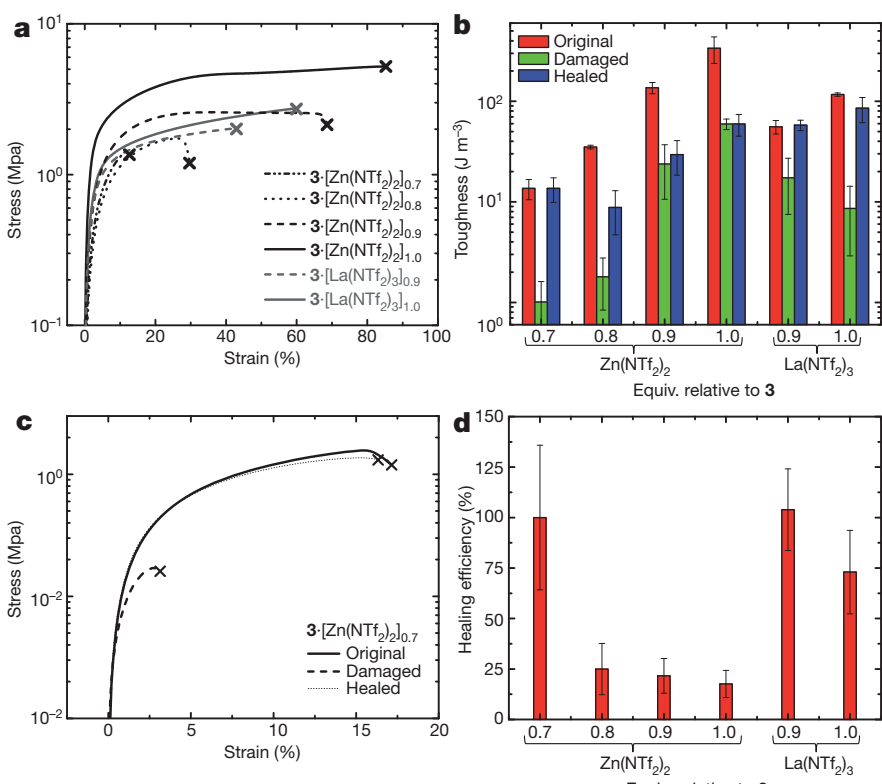

Figure 3 Mechanical properties and healing of the metallosupramolecular polymers. a, Stress-strain curves of metallosupramolecular polymers of $\mathbf{3}$ and varying amounts of $\mathrm{Zn}\left(\mathrm{NTf}_{2}\right)_{2}$ or $\mathrm{La}\left(\mathrm{NTf}_{2}\right)_{3}$. $\mathbf{b}$, Toughness of metallosupramolecular polymers of 3 and varying amounts of $\mathrm{Zn}\left(\mathrm{NTf}_{2}\right)_{2}$ or $\mathrm{La}\left(\mathrm{NTf}_{2}\right)_{3}\left(n=3-5\right.$ for $\mathbf{3} \cdot\left[\mathrm{Zn}\left(\mathrm{NTf}_{2}\right)_{2}\right]_{0.8}, \mathbf{3} \cdot\left[\mathrm{Zn}\left(\mathrm{NTf}_{2}\right)_{2}\right]_{0.9}, \mathbf{3} \cdot\left[\mathrm{Zn}\left(\mathrm{NTf}_{2}\right)_{2}\right]_{1.0}$ and $3 \cdot\left[\mathrm{La}\left(\mathrm{NTf}_{2}\right)_{3}\right]_{1.0} ; n=10-13$ for $3 \cdot\left[\mathrm{Zn}\left(\mathrm{NTf}_{2}\right)_{2}\right]_{0.7}$ and $\mathbf{3} \cdot\left[\mathrm{La}\left(\mathrm{NTf}_{2}\right)_{3}\right]_{0.9}$; error bars, s.d.). c, Stress-strain curves of films of $3 \cdot\left[\mathrm{Zn}\left(\mathrm{NTf}_{2}\right)_{2}\right]_{0.7}$; shown are data for original, damaged, and healed samples. $\mathbf{d}$, Healing efficiency of films of $\mathbf{3}$ and varying amounts of $\mathrm{Zn}\left(\mathrm{NTf}_{2}\right)_{2}$ or $\mathrm{La}\left(\mathrm{NTf}_{2}\right)_{3}$. Error bars, s.d.

transitions at -51 and $47^{\circ} \mathrm{C}$, which by comparison with 2 and previous data ${ }^{16}$ are assigned as the $T_{\mathrm{g}}$ values of the poly(ethylene-cobutylene) core and of the melting of phase-separated Mebip domains, respectively. The metallopolymers $3 \cdot\left[\mathrm{Zn}\left(\mathrm{NTf}_{2}\right)_{2}\right]_{x}$ show similar MDSC traces but do not show melting of uncomplexed Mebip domains. However, DMTA traces show the $T_{\mathrm{g}}$ of the poly(ethyleneco-butylene) core to be around $-23^{\circ} \mathrm{C}$, with a weaker transition at around $\sim 50^{\circ} \mathrm{C}$, consistent with the thermal transition associated with the uncomplexed Mebip domains. At $25^{\circ} \mathrm{C}$, the polymers display storage moduli between 60 and $53 \mathrm{MPa}$ with little dependence on the $\mathrm{Zn}^{2+}: 3$ ratio. The storage modulus drops above $\sim 50^{\circ} \mathrm{C}$ for polymers with non-stoichiometric $\mathrm{Zn}^{2+}: 3$ ratios and above $100{ }^{\circ} \mathrm{C}$ for all materials, indicative of depolymerization at higher temperatures. Stress-strain experiments conducted at $25^{\circ} \mathrm{C}$ show a pronounced decrease in strength, elongation at break and toughness as the $\mathrm{Zn}^{2+}: 3$ ratio is decreased (Fig. 3a, b), consistent with a decrease in molecular mass and long-range order (Fig. 2a, b and Supplementary Fig. 2) as the stoichiometric balance of metal and ligand is offset.

The optical absorption spectrum of $\mathbf{3}$ has a band with a maximum at $313 \mathrm{~nm}$ that is characteristic of Mebip (Supplementary Fig. 5). On complexation of 3 with $\mathrm{Zn}\left(\mathrm{NTf}_{2}\right)_{2}$, this band weakens and a new peak, at $341 \mathrm{~nm}$, appears. A titration series shows an isosbestic point at $328 \mathrm{~nm}$, reflecting a well-defined equilibrium between free and metalcoordinated ligands. The absorption spectra of films of $\mathbf{3}$ and $3 \cdot\left[\mathrm{Zn}\left(\mathrm{NTf}_{2}\right)_{2}\right]_{x}$ have similar features (Supplementary Fig. 6). Lowmolecular-mass $\mathrm{Zn}^{2+}$-Mebip complexes fluoresce weakly, suggesting that a considerable portion of absorbed light is converted into heat. The optical healing pursued here is based on the assumption that this energy could be harnessed to locally dissociate the supramolecular motif and disengage the macromonomer ends from the hard phase (Fig. 1a), resulting in a decrease in the supramolecular polymer's molecular mass and liquefying the material. 
To test this hypothesis, we deliberately damaged 350-400- $\mu$ m-thick films of the polymers based on 3 and $0.7-1.0$ equiv. of $\mathrm{Zn}\left(\mathrm{NTf}_{2}\right)_{2}$ by applying well-defined cuts with a depth of $\sim 50-70 \%$ of the film thickness. These samples were subsequently exposed to ultraviolet radiation with a wavelength of $320-390 \mathrm{~nm}$ and an intensity of $950 \mathrm{~mW} \mathrm{~cm}^{-2}$. Pictures of films made of $\mathbf{3} \cdot\left[\mathrm{Zn}\left(\mathrm{NTf}_{2}\right)_{2}\right]_{0.7}$ suggest that under these conditions two consecutive exposures of $30 \mathrm{~s}$ are sufficient to heal the cuts completely (Fig. 2c). Materials with higher metal contents healed less well. Slight discolouration of the samples on ultraviolet irradiation was observed, and increased with exposure time; this may reflect photooxidative stress, which is not surprising given the light intensity, the temperature, the presence of air and possibly residual double bonds in the poly(ethylene-co-butylene) core. Figure 2e shows that it was readily possible to heal a $3 \cdot\left[\mathrm{Zn}\left(\mathrm{NTf}_{2}\right)_{2}\right]_{0.7}$ film while applying a stress of $\sim 8 \mathrm{kPa}$, by irradiating only the damaged portion. The extinction coefficient of the metallopolymer films is $\sim 890 \mathrm{~cm}^{-1}$, and light absorption and heat generation therefore occur predominantly at the surface. In situ experiments revealed that under the conditions employed here for healing, the surface temperature of a $3 \cdot\left[\mathrm{Zn}\left(\mathrm{NTf}_{2}\right)_{2}\right]_{0.7}$ film rose to over $220^{\circ} \mathrm{C}$ in $30 \mathrm{~s}$ and slightly higher on longer irradiation (Fig. 2d). We qualitatively confirmed that $3 \cdot\left[\mathrm{Zn}\left(\mathrm{NTf}_{2}\right)_{2}\right]_{0.7}$ films also healed on heating to $\sim 190^{\circ} \mathrm{C}$, which supports the idea that the light-induced healing is indeed due to photothermal conversion. Reference experiments in which $3 \cdot\left[\mathrm{Zn}\left(\mathrm{NTf}_{2}\right)_{2}\right]_{0.7}$ films were irradiated with light of similar intensity but a wavelength outside the absorption band of the metalligand complex showed no healing, confirming that the process is indeed due to absorption by the metal-ligand complex and not to infrared heating (Supplementary Fig. 7).

To determine the healing efficiency of $\mathbf{3} \cdot\left[\mathrm{Zn}\left(\mathrm{NTf}_{2}\right)_{2}\right]_{x}$ in a quantitative manner, films were damaged and healed as described above. We conducted stress-strain experiments on 'original', 'damaged' and 'healed' samples, and the healing efficiency was expressed using toughness as the figure of merit:

$$
\text { healing efficiency }=100 \% \frac{\text { toughness }_{\text {healed }}}{\text { toughness }_{\text {original }}}
$$

Here toughness $s_{\text {healed }}$ is the toughness of the healed sample set and toughness original $_{\text {is }}$ the toughness of the original sample set.

Figure $3 \mathrm{~b}$ shows that the strain and stress at break of a $3 \cdot\left[\mathrm{Zn}\left(\mathrm{NTf}_{2}\right)_{2}\right]_{0.7}$ film (and, hence, toughness, which is proportional to the area under the stress-strain curve) are significantly reduced on damaging the samples as described above. However, the original properties could be restored on ultraviolet irradiation. Statistical experiments (Fig. 3b, d and Supplementary Tables 2 and 3) show that

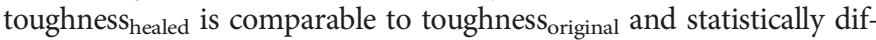
ferent from the toughness of the damaged sample set, with a healing efficiency of $100 \pm 36 \%$. Lower healing efficiencies, of $25 \pm 12 \%$, $22 \pm 8.6 \%$ and $18 \pm 6.7 \%$, were observed for $3 \cdot\left[\mathrm{Zn}\left(\mathrm{NTf}_{2}\right)_{2}\right]_{0.8}$, $3 \cdot\left[\mathrm{Zn}\left(\mathrm{NTf}_{2}\right)_{2}\right]_{0.9}$ and 3. $\left[\mathrm{Zn}\left(\mathrm{NTf}_{2}\right)_{2}\right]_{1.0}$, respectively. This is consistent with the greatest viscosity reduction being for $\mathbf{3} \cdot\left[\mathrm{Zn}\left(\mathrm{NTf}_{2}\right)_{2}\right]_{0.7}$, on account of the excess of free ligands, which render the system more dynamic and lower the viscosity. However, the concomitant decrease in molecular mass and long-range order also lower the toughness as the $\mathrm{Zn}^{2+}: 3$ ratio is decreased (Fig. 3a, b).

As $\mathrm{La}^{3+}$-Mebip complexes are more labile and dissociate at lower temperatures than $\mathrm{Zn}^{2+}$-Mebip complexes ${ }^{13}$, we also studied polymers based on 3 and 1.0 or 0.9 equiv. of $\mathrm{La}\left(\mathrm{NTf}_{2}\right)_{3}\left(3 \cdot\left[\mathrm{La}\left(\mathrm{NTf}_{2}\right)_{3}\right]_{1.0}\right.$ and $\left.3 \cdot\left[\mathrm{La}\left(\mathrm{NTf}_{2}\right)_{3}\right]_{0.9}\right)$. Titration experiments confirmed that the La$\operatorname{MeBip}\left(\mathrm{NTf}_{2}\right)_{3}$ complexes involve 1:3 binding (Supplementary Fig. 9), suggesting the formation of network structures. Nevertheless, SAXS and TEM data reveal the formation of a predominantly lamellar morphology (Fig. 4a, b) with a period of $7.4 \mathrm{~nm}$ (SAXS data for
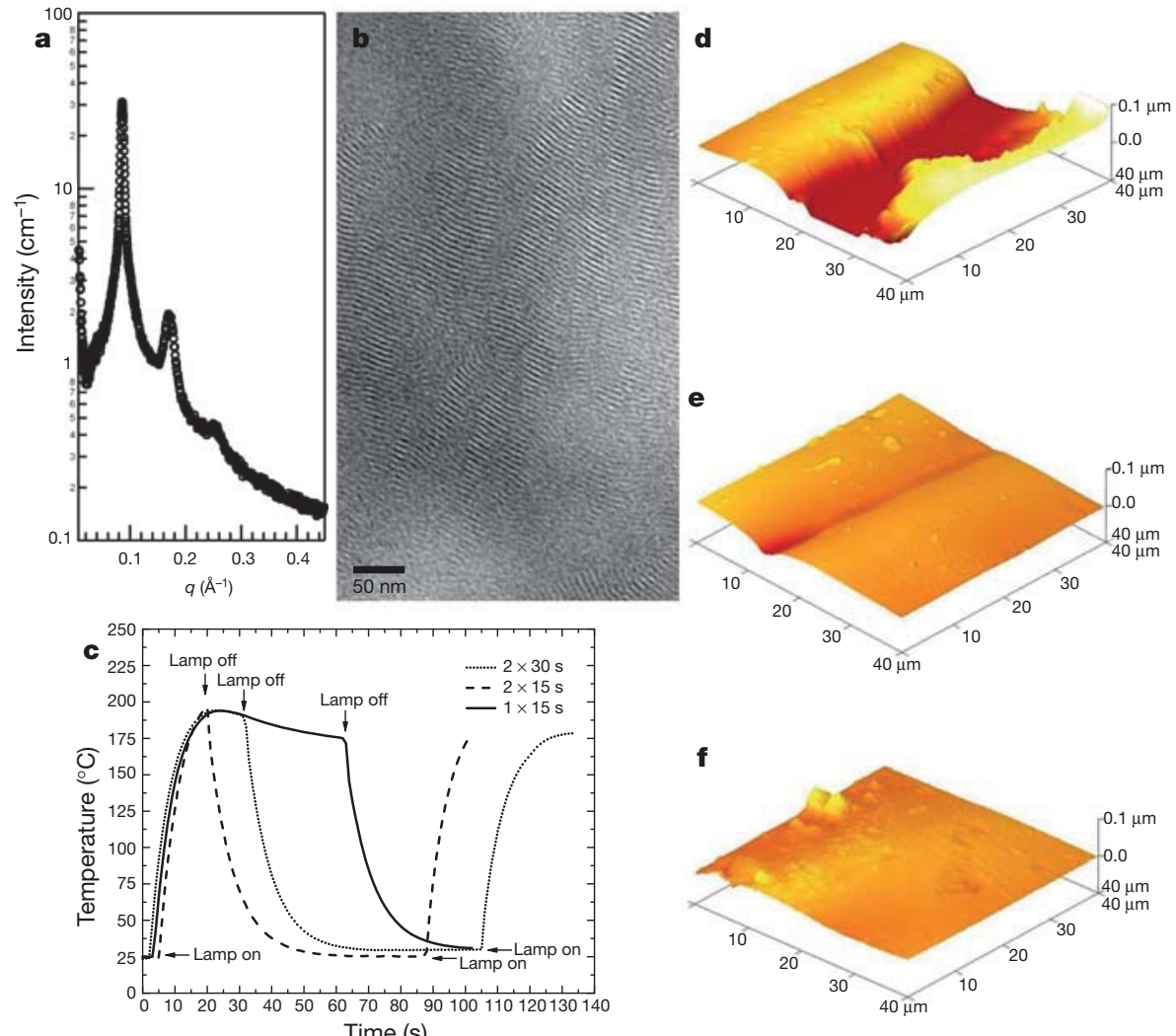

Figure $4 \mid$ Characterization of La-based metallosupramolecular polymers. a, SAXS data for metallosupramolecular polymers of 3・[La( $\left.\left.\mathrm{NTf}_{2}\right)_{3}\right]_{1.0}$. b, Representative TEM micrograph showing the lamellar morphology observed in $3 \cdot\left[\mathrm{La}\left(\mathrm{NTf}_{2}\right)_{3}\right]_{1.0}$. c c Temperature of a $3 \cdot\left[\mathrm{La}(\mathrm{NTf})_{3}\right]_{0.9}$ film on exposure to healing conditions, measured using an infrared camera. d-f, AFM images of a damaged $\mathbf{3} \cdot\left[\mathrm{La}\left(\mathrm{NTf}_{2}\right)_{3}\right]_{1.0}$ film before healing $(\mathbf{d})$, after partial healing $(\mathbf{e})$ and after complete healing $(\mathbf{f})$. 
3. $\left.\left[\mathrm{La}\left(\mathrm{NTf}_{2}\right)_{3}\right]_{1.0}\right)$. The mechanical properties of $\mathbf{3} \cdot\left[\mathrm{La}\left(\mathrm{NTf}_{2}\right)_{3}\right]_{x}$ are similar to those of $\mathbf{3} \cdot\left[\mathrm{Zn}\left(\mathrm{NTf}_{2}\right)_{2}\right]_{0.9}$ (Fig. 3 and Supplementary Fig. 11 ), but their healing efficiencies, of $104 \pm 20 \%$ and $73 \pm 21 \%$, for 3. $\left[\mathrm{La}\left(\mathrm{NTf}_{2}\right)_{3}\right]_{0.9}$ and $3 \cdot\left[\mathrm{La}\left(\mathrm{NTf}_{2}\right)_{3}\right]_{1.0}$, respectively (Fig. 3b, d), are much better. The surface temperature of $3 \cdot\left[\mathrm{La}\left(\mathrm{NTf}_{2}\right)_{3}\right]_{0.9}$ during photohealing, of $\sim 195^{\circ} \mathrm{C}$ (Fig. 4c), was lower than that of $3 \cdot\left[\mathrm{Zn}\left(\mathrm{NTf}_{2}\right)_{2}\right]_{0.7}$, and optical microscopy showed qualitatively that the former liquefied more readily, consistent with the weaker and more dynamic binding. Thus, $3 \cdot\left[\mathrm{La}\left(\mathrm{NTf}_{2}\right)_{3}\right]_{0.9}$ shows the best combination of high toughness and high healing efficiency, which seems to be related to the more dynamic nature of $\mathrm{La}-\mathrm{MeBip}$ complexes relative to $\mathrm{Zn}$-MeBip complexes. We used atomic force microscopy (AFM) to probe the topology of a $3 \cdot\left[\mathrm{La}\left(\mathrm{NTf}_{2}\right)_{3}\right]_{1.0}$ film around a defect before and after healing (Fig. $4 \mathrm{~d}-\mathrm{f}$ ). The images show that the cut is filled and disappears, consistent with the proposed viscosity decrease on exposure to light.

Our systematic investigation of several strategically chosen compositions and in-depth morphological studies provide insight into the healing process in these metallosupramolecular polymers, based on a previously unexplored combination of supramolecular polymerization and the concept of light-heat conversion. The formation of lamellar morphologies in which a hard phase comprising the metal-ligand complexes physically crosslinks soft domains of the poly(ethylene-cobutylene) cores is the main determinant for the thermomechanical characteristics of the materials studied. The data suggest that the dynamics of the light-induced depolymerization and, thereby, the healing behaviour are governed by the presence of an excess of free ligands and the nature of the metal-ligand bond. The concept of photothermally induced healing of supramolecular materials seems to be applicable to any supramolecular polymer with a binding motif that is sufficiently dynamic. The ability to change the chromophore makes it possible to tailor the wavelength required for healing. The combination of the new approach with an additional mechanochromic response $e^{24,25}$ promises access to true-that is, autonomously functioning-selfhealing materials, in which light is absorbed only at defect sites.

\section{METHODS SUMMARY}

We synthesized macromonomer 3 (number-average molecular mass, $M_{\mathrm{n}}=4,800 \mathrm{~g} \mathrm{~mol}^{-1}$ ) via a Mitsunobu reaction of $\mathbf{1}$ and hydroxyl-terminated poly (ethylene-co-butylene) $\left(2, M_{\mathrm{n}}=4,000 \mathrm{~g} \mathrm{~mol}^{-1}\right) \cdot \mathbf{3} \cdot\left[\mathrm{Zn}\left(\mathrm{NTf}_{2}\right)_{2}\right]_{x}$ and $\mathbf{3} \cdot\left[\mathrm{La}\left(\mathrm{NTf}_{2}\right)_{3}\right]_{x}$ were formed by combining 3 with $\mathrm{Zn}\left(\mathrm{NTf}_{2}\right)_{2}$ or $\mathrm{La}\left(\mathrm{NTf}_{2}\right)_{3}$ in a $\mathrm{CH}_{3} \mathrm{Cl} / \mathrm{CH}_{3} \mathrm{CN}$ mixture. Films 350-400 $\mu \mathrm{m}$ thick were produced by casting and drying these solutions and compression moulding the resulting solids at $120^{\circ} \mathrm{C}$. The thermomechanical properties were characterized by MDSC and DMTA under $\mathrm{N}_{2}$ at heating rates of $3{ }^{\circ} \mathrm{C} \mathrm{min}{ }^{-1}$. Stress-strain experiments were conducted at $25^{\circ} \mathrm{C}$ with a strain rate of $5 \% \mathrm{~min}^{-1}$, on 'dog-bone-shaped' samples (Supplementary Fig. 8). Damage to the film was applied by cutting the samples to a depth of 50-70\% with a razor blade. Samples were healed by exposure to light of wavelength $320-390 \mathrm{~nm}$ and intensity $950 \mathrm{~mW} \mathrm{~cm}^{-2}$. Mechanical data are averages of $n=3-5$ independent experiments for 3. $\left[\mathrm{Zn}\left(\mathrm{NTf}_{2}\right)_{2}\right]_{0.8}, \mathbf{3} \cdot\left[\mathrm{Zn}\left(\mathrm{NTf}_{2}\right)_{2}\right]_{0.9}, \mathbf{3} \cdot\left[\mathrm{Zn}\left(\mathrm{NTf}_{2}\right)_{2}\right]_{1.0}$ and $\mathbf{3} \cdot\left[\mathrm{La}\left(\mathrm{NTf}_{2}\right)_{3}\right]_{1.0}$, and $n=10-13$ independent experiments for $3 \cdot\left[\mathrm{Zn}\left(\mathrm{NTf}_{2}\right)_{2}\right]_{0.7}$ and $3 \cdot\left[\mathrm{La}\left(\mathrm{NTf}_{2}\right)_{3}\right]_{0.9}$. All errors are standard deviations. On account of the destructive nature of the stressstrain experiments, different samples from the same batch were used to measure the materials in their original, damaged and healed states. To account for the thickness variation between samples, force-displacement curves were divided by the nominal cross-sectional area of the sample (assuming no defect for damaged and healed samples) to yield stress-strain curves. These were integrated to yield toughness as a figure of merit, allowing comparison of original, damaged and healed samples. We characterized morphology using SAXS, TEM and AFM. Surface temperatures were determined with an infrared camera.

Full Methods and any associated references are available in the online version of the paper at www.nature.com/nature.

\section{Received 20 September 2010; accepted 15 February 2011.}

1. Blaiszik, B. J.etal. Self-healing polymers and composites. Annu. Rev. Mater. Res. $\mathbf{4 0}$ 179-211 (2010)

2. Bergman, S. D. \& Wudl, F. Mendable polymers. J. Mater. Chem. 18, 41-62 (2008)

3. Wool, R. P. Self-healing materials: a review. Soft Matter 4, 400-418 (2008).
4. Murphy, E. B. \& Wudl, F. The world of smart healable materials. Prog. Polym. Sci. 35, 223-251 (2010)

5. Cordier, P., Tournilhac, F., Soulie-Ziakovic, C. \& Leibler, L. Self-healing and thermoreversible rubber from supramolecular assembly. Nature 451, 977-980 (2008).

6. Kim, Y. H. \& Wool, R. P. A theory of healing at a polymer-polymer interface. Macromolecules 16, 1115-1120 (1983).

7. Chen, X. et al. A thermally re-mendable cross-linked polymeric material. Science 295, 1698-1702 (2002).

8. Murphy, E. B. et al. Synthesis and characterization of a single-component thermally remendable polymer network: Staudinger and Stille revisted. Macromolecules 41, 5203-5209 (2008).

9. Burattini, S. et al. A self-repairing, supramolecular polymer system: healability as a consequence of donor-acceptor pi-pi stacking interactions. Chem. Commun. (Camb.)6717-6719 (2009).

10. Burattini, S. et al. A healable supramolecular polymer blend based on aromatic $\pi-\pi$ stacking and hydrogen-bonding interactions. J. Am. Chem. Soc. 132 , 12051-12058 (2010)

11. Wojtecki, R. J., Meador, M. A. \& Rowan, S. J. Utilizing the dynamic bond to access macroscopically-responsive structurally-dynamic polymers. Nature Mater. 10, 14-27 (2011).

12. Bosman, A. W., Sijbesma, R. P. \& Meijer, E. W. Supramolecular polymers at work. Mater. Today 7, 34-39 (2004).

13. Kumpfer, J. R., Jin, J. Z. \& Rowan, S. J. Stimuli-responsive europium-containing metallo-supramolecular polymers. J. Mater. Chem. 20, 145-151 (2010).

14. Sivakova, S., Bohnsack, D. A., Mackay, M. E., Suwanmala, P. \& Rowan, S. J. Utilization of a combination of weak hydrogen-bonding interactions and phase segregation to yield highly thermosensitive supramolecular polymers. J. Am. Chem. Soc. 127, 18202-18211 (2005)

15. Ghosh, B. \& Urban, M. W. Self-repairing oxetane-substituted chitosan polyurethane networks. Science 323, 1458-1460 (2009).

16. Kautz, H., van Beek, D. J. M., Sijbesma, R. P. \& Meijer, E. W. Cooperative end-to-end and lateral hydrogen-bonding motifs in supramolecular thermoplastic elastomers. Macromolecules 39, 4265-4267 (2009).

17. Beck, J. B., Ineman, J. M. \& Rowan, S. J. Metal/ligand-induced formation of metallosupramolecular polymers. Macromolecules 38, 5060-5068 (2005).

18. Burnworth, M., Knapton, D., Rowan, S. J. \& Weder, C. Metallo-supramolecular polymerization: a route to easy-to-process organic/inorganic hybrid materials. J. Inorg Organomet Polym Mater. 17, 91-103 (2007)

19. Burnworth, M., Mendez, J. D., Schroeter, M., Rowan, S. J. \& Weder, C. Decoupling optical properties in metallo-supramolecular poly(p-phenylene ethynylene)s. Macromolecules 41, 2157-2163 (2008).

20. Knapton, D., Rowan, S. J. \& Weder, C. Synthesis and properties of metallosupramolecular poly(p-phenylene ethynylene)s. Macromolecules 39, 651-657 (2006).

21. Knapton, D., Iyer, P. K., Rowan, S. J. \& Weder, C. Synthesis and properties of metallosupramolecular poly(p-xylylene)s. Macromolecules 39, 4069-4074 (2006).

22. Knapton, D., Burnworth, M., Rowan, S. J. \& Weder, C. Fluorescent organometallic sensors for the detection of chemical-warfare-agent mimics. Angew. Chem. Int. Ed. 45, 5825-5829 (2006).

23. Beck, J. B. \& Rowan, S. J. Metal-ligand induced supramolecular polymerization: a route to responsive materials. Faraday Discuss. 128, 43-53 (2005).

24. Kunzelman, J., Kinami, M., Crenshaw, B. R., Protasiewicz, J. D. \& Weder, C. Oligo(pphenylene vinylene)s as a "new" class of piezochromic fluorophores. Adv. Mater. 20, 119-122 (2008).

25. Crenshaw, B. R. et al. Deformation-induced color changes in mechanochromic polyethylene blends. Macromolecules 40, 2400-2408 (2007).

Acknowledgements This material is based on work supported by the US Army Research Office (W911NF-09-1-0288 and W911NF-06-1-0414); the National Science Foundation under grant numbers CHE-0704026, DMR-0602869 and MRI-0821515; the Adolphe Merkle Foundation; and the Postgraduate Research Participation Program at the US Army Research Laboratory, administered by the Oak Ridge Institute of Science and Education through an interagency agreement between the US Department of Energy and Army Research Laboratory (contract number

ORISE-1120-1120-99). We thank S. Dellinger for the design and the fabrication of a device to introduce well-defined defects and Kraton Performance Polymers Inc for the donation of the hydroxyl-terminated poly(ethylene-co-butylene).

Author Contributions M.B., L.T. and J.R.K. developed the procedures for synthesis and characterization of 3. M.B. prepared and processed all supramolecular polymers. M.B. and G.L.F. did the MDSC experiments. A.J.D. and F.L.B. carried out the TEM and SAXS experiments. M.B. did the mechanical testing. G.L.F. carried out the light-heat conversion experiments. M.B. conducted the photohealing experiments. S.J.R. and C.W. designed the study. All authors discussed results and contributed to the interpretation of data. M.B., S.J.R. and C.W. wrote the paper. All authors contributed to editing the manuscript.

Author Information Reprints and permissions information is available at www.nature.com/reprints. The authors declare no competing financial interests. Readers are welcome to comment on the online version of this article at www nature.com/nature. Correspondence and requests for materials should be addressed to S.J.R. (stuart.rowan@case.edu) or C.W. (christoph.weder@unifr.ch). 


\section{METHODS}

General methods. ${ }^{1} \mathrm{H}$ and ${ }^{13} \mathrm{C}$ NMR spectra were acquired in $\mathrm{CDCl}_{3}$ using a Varian $600-\mathrm{MHz}$ spectrometer; chemical shifts $(\delta)$ are expressed in parts per million relative to an internal TMS standard. Mass spectra were obtained using a Bruker AUTOFLEX III MALDI TOF/TOF mass spectrometer using dithranol as a matrix. Size exclusion chromatography (SEC) of macromonomer 3 was conducted on a Visotek Model 270 Dual Detector, equipped with Varian OligoPore and ResiPore SEC/GPC columns. Ultraviolet-visible absorption spectra were obtained on a Perkin-Elmer Lambda 800 spectrometer. MDSC experiments were carried out under nitrogen on TA Instrument DSCQ2000 at a heating rate of $3{ }^{\circ} \mathrm{Cmin}^{-1}$. DMTA measurements were conducted under nitrogen on a PerkinElmer Q800 spectrometer at a heating rate of $3{ }^{\circ} \mathrm{C} \mathrm{min}^{-1}$. Stress-strain experiments were conducted on the same instrument at a temperature of $25^{\circ} \mathrm{C}$ and a strain rate of $5 \% \mathrm{~min}^{-1}$. Surface temperatures of thin films were determined with an Optris PI Connect infrared camera from Roth and Co AG (Oberuzwil).

Synthesis of macromonomer 3. To a stirred solution of 2,6-bis ( $1^{\prime}$-methylbenzimidazolyl)-4-hydroxypyridine ${ }^{26}(2.30 \mathrm{~g}, 6.47 \mathrm{mmol})$, triphenylphosphine $(3.40 \mathrm{~g}$, $13.0 \mathrm{mmol})$, hydroxyl-terminated poly(ethylene-co-butylene) $\left(M_{\mathrm{n}}=4,000 \mathrm{~g} \mathrm{~mol}^{-1}\right.$, $9.1 \mathrm{~g}, 2.0 \mathrm{mmol}$; donated by Kraton) in dry THF ( $120 \mathrm{ml}), 5 \mathrm{ml}$ of diethyl azodicarboxylate (DEAD) $40 \mathrm{wt} \%$ in toluene was added at $-40^{\circ} \mathrm{C}$. After $4 \mathrm{~h}$ the reaction mixture was allowed to warm to $25^{\circ} \mathrm{C}$ and was left to react at this temperature for $44 \mathrm{~h}$. The solvents were then evaporated in vacuum and the remaining residue was redissolved in hot hexanes $(150 \mathrm{ml})$ and washed three times with $\mathrm{MeOH}$ and three times with $1 \mathrm{M} \mathrm{NaOH}(\mathrm{aq}$.$) . The product was purified by column chromatography$ $\left(\mathrm{CHCl}_{3}, \mathrm{SiOH}\right)$, dried overnight and collected as a tacky white solid $(9.0 \mathrm{~g}, 81 \%$ yield $)$. ${ }^{1} \mathrm{H} \mathrm{NMR}\left(600 \mathrm{MHz}, \mathrm{CDCl}_{3}, 18^{\circ} \mathrm{C}\right): \delta=7.930(\mathrm{~s}, 4 \mathrm{H}), 7.871(\mathrm{~d}, J=7.8 \mathrm{~Hz}, 4 \mathrm{H}), 7.463$ $(\mathrm{d}, J=7.8 \mathrm{~Hz}, 4 \mathrm{H}), 7.382(\mathrm{~m}, 4 \mathrm{H}), 7.351(\mathrm{~m}, 4 \mathrm{H}), 4.239(\mathrm{~s}, 12 \mathrm{H}), 4.252(\mathrm{t}, 4 \mathrm{H}), 1.480$ $0.935(\mathrm{~m}, 438 \mathrm{H}), 0.935-0.79(\mathrm{~m}, 138 \mathrm{H}) .{ }^{13} \mathrm{C} \mathrm{NMR}\left(100 \mathrm{MHz}, \mathrm{CDCl}_{3}, 18{ }^{\circ} \mathrm{C}\right)$ : $\delta=166.67,151.01,150.45,142.47,137.15,123.50,122.78,120.13,111.78,109.89$, 68.680, 39.040-37.808, 36.039, 33.380, 33.190, 32.531, 30.650, 30.194, 29.738, $26.745-25.822,10.860-10.196$. As determined by NMR, $X_{\mathrm{n}}=72$ (number-average degree of polymerization) and $M_{\mathrm{n}}=4,800 \mathrm{~g} \mathrm{~mol}^{-1}$. As determined by SEC, $M_{\mathrm{n}}=6,950 \mathrm{~g} \mathrm{~mol}^{-1}, M_{\mathrm{w}}=7,080 \mathrm{~g} \mathrm{~mol}^{-1}$ (weight average) and PDI $=1.02$ (polydispersity index).

Supramolecular polymerization and film formation. To a stirred solution of 3 in $\mathrm{CHCl}_{3}, \sim 0.025 \mathrm{M}$, a solution of $\mathrm{Zn}\left(\mathrm{NTf}_{2}\right)_{2}$ or $\mathrm{La}\left(\mathrm{NTf}_{2}\right)_{3}$ in $\mathrm{CH}_{3} \mathrm{CN}, \sim 0.05 \mathrm{M}$, was added. The amount of metal added was adjusted to provide for metal:3 equivalents of 1.0-0.7 (accounting for 1:2 and 1:3 binding, respectively), within an error of $\sim 5 \%$. On addition of the metal salt, a white precipitate formed. This precipitate subsequently dissolved in $15 \mathrm{~s}$ for the $\mathrm{Zn}^{2+}$ systems and an increase of the solutions viscosity was observed. The $\mathrm{La}^{3+}$ systems led to homogenous gels after $5 \mathrm{~min}$ of stirring. The solutions were then dried in vacuum to produce the supramolecular polymers $3 \cdot\left[\mathrm{Zn}\left(\mathrm{NTf}_{2}\right)_{2}\right]_{x}$ and $\mathbf{3} \cdot\left[\mathrm{La}\left(\mathrm{NTf}_{2}\right)_{3}\right]_{x}$, which were subsequently compression moulded at $120^{\circ} \mathrm{C}$ and a pressure of $3 \mathrm{t}$ for $10 \mathrm{~min}$ to produce $350-400-\mu \mathrm{m}$-thick films. To conduct optical absorption experiments, films of a thickness of 2.7-6.3 $\mu \mathrm{m}$ were prepared by dissolving the polymers in $\mathrm{CHCl}_{3}$ (concentration, $25 \mathrm{mg} \mathrm{ml}^{-1}$ ) and spin coating.

Mechanical testing. The mechanical properties of films of $3 \cdot\left[\mathrm{Zn}\left(\mathrm{NTf}_{2}\right)_{2}\right]_{x}$ and $3 \cdot\left[\mathrm{La}\left(\mathrm{NTf}_{2}\right)_{3}\right]_{x}$ were tested by DMTA using either a controlled-frequency temperature sweep or a controlled strain rate at constant temperature. The temperature sweeps were conducted under $\mathrm{N}_{2}$ with a frequency of $1 \mathrm{~Hz}$ and a heating rate of $3{ }^{\circ} \mathrm{C} \mathrm{min}^{-1}$ from $-100{ }^{\circ} \mathrm{C}$ to $100^{\circ} \mathrm{C}$. Stress-strain data were collected under $\mathrm{N}_{2}$ at $25^{\circ} \mathrm{C}$, with a strain rate of $5 \% \mathrm{~min}^{-1}$. All mechanical tests were conducted on dogbone-shaped samples (Supplementary Fig. 8). Different samples from the same batch were used to measure the materials in their original, damaged and healed states.

Film damaging and healing. Films of $\mathbf{3} \cdot\left[\mathrm{Zn}\left(\mathrm{NTf}_{2}\right)_{2}\right]_{x}$ and $\mathbf{3} \cdot\left[\mathrm{La}\left(\mathrm{NTf}_{2}\right)_{3}\right]_{x}$ were damaged by cutting the samples to a depth of $\sim 50-70 \%$ of their thickness with a razor blade attached to a calliper, which allowed for specific depth control. These samples were then exposed to a filtered light source (Bluepoint 4 Ecocure from Honle UV America), which irradiated the samples with wavelengths of light from 320 to $390 \mathrm{~nm}$ at an intensity of $950 \mathrm{~mW} \mathrm{~cm}^{-2}$. Reference experiments were conducted with the same lamp system, but with a filter that changed the wavelength to $400-500 \mathrm{~nm}$.

Morphology characterization. SAXS data were collected using a Molecular Metrology 120-mm-diameter detector, Ni-filtered $\mathrm{Cu}_{\mathrm{K} \alpha} \mathrm{X}$-ray radiation $(\lambda=1.542 \AA)$ produced using a Rigaku Ultrax18 X-ray generator, and sampleto-detector distances of 150 and $50 \mathrm{~cm}$. The instrument was calibrated using $\mathrm{Ag}$ behenate and glassy carbon standards. The data were corrected for sample absorption and background noise before scaling to absolute intensity $\left(\mathrm{cm}^{-1}\right)$. The twodimensional data sets were azimuthally averaged to give intensity as a function of the magnitude of the scattering vector, $q$, where $q=4 \pi \sin (\theta) / \lambda$ and $2 \theta$ is the scattering angle. All data processing and analysis were performed using IGOR PRO 6 (WaveMetrics) and tool suites developed in ref. 27. Bragg diffraction maxima were fitted using Lorentzian distributions. TEM was performed using a JEOL JEM-2100F field-emission TEM operated at $200 \mathrm{kV}$. Sections approximately 50-70-nm thick were prepared for TEM by ultramicrotomy using a Leica UCT ultracryomicrotome. Bright-field images were collected with a Gatan SC1000 Orius 11-megapixel charge-coupled-device camera and analysed using Gatan DIGITALMICROGRAPH software. AFM data were collected on a Veeco MultiMode V AFM run in tapping mode.

26. Beck, J. B. \& Rowan, S. J. Multistimuli, multiresponsive metallo-supramolecular polymers. J. Am. Chem. Soc. 125, 13922-13923 (2003).

27. Ilavsky, J. \& Jemian, P. R. Irena: tool suite for modelling and analysis of small angle scattering. J. Appl. Crystallogr. 42, 347-353 (2009). 